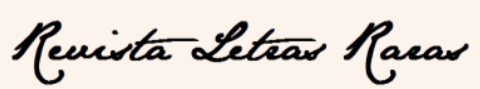

ISSN: $2317-2347$ - v. 7, n. 2 (2018)

\title{
Da leitura à produção textual: reflexões sobre uma prática de ensino
}

\author{
de texto / From reading to textual production: reflections on a practice of \\ text teaching
}

\author{
Adauto Locatelli Taufer* \\ Amelia Biesek Lovatto** \\ Daniela Favero Netto ${ }^{* * *}$
}

\begin{abstract}
RESUMO
Este relato de experiência apresenta uma prática desenvolvida com alunos do $3^{\circ}$ Ano do Ensino Médio do Colégio de Aplicação da UFRGS, no primeiro semestre de 2017. O objetivo inicial dessa prática foi o de investigar o papel da leitura pública como encaminhamento de reescrita, partindo da hipótese de que a leitura em voz alta se configuraria como nível intermediário entre a presença do interlocutor, característica da fala, e a sua ausência, condição da escrita (ENDRUWEIT e NUNES, 2013). Dessa forma, o momento de abstrações e de ausências da escrita é preenchido com a presença de um interlocutor, de um momento e de um espaço real, quais sejam: os colegas e a sala de aula, contribuindo com o aprimoramento da escrita. Os textos escritos foram norteados pela proposta de Guedes (2009), que orienta a produção de narração, de descrição e de dissertação, para desenvolver as seguintes qualidades discursivas: unidade temática, questionamento, concretude e objetividade. No entanto, os alunos demonstraram dificuldades em apresentar as qualidades discursivas nos seus textos, o que nos levou a buscar outras estratégias para o ensino da escrita, como a análise de outras produções textuais para além das produzidas para a esfera da sala de aula, ou seja, foram trazidos para estudo textos de outros autores. Além disso, outras atividades, como a revisão entre pares, tiveram importância no processo de escrita e de reescrita. A necessidade dessas atividades traz, portanto, uma nova problematização: quais atividades de leitura, além da leitura em voz alta, podem ser realizadas para que haja interlocução real no texto escolar? PALAVRAS-CHAVE: Ensino-aprendizagem de texto; Leitura; Escrita
\end{abstract}

\begin{abstract}
This experience report presents a practice developed for High School senior students at Colégio de Aplicação of UFRGS. The classes happened in the first semester of 2017. The initial objective was to investigate how the practice of reading aloud the texts produced by the students during classes influences the rewriting process. This practice comes from the hypothesis that reading the texts aloud during class might balance the presence of interlocutor (oral language characteristic) and its absence (written language condition)(ENDRUWEIT and NUNES, 2013). According to the authors, the reading moment would fulfill the abstractions and absences, of which the written language is consisted, with a real presence - the classmates -, and a real space - the classroom, which gives the students a place to speak from and people to speak with. Furthermore, the students should write their texts based on the method presented by Guedes (2009), which consists of writing narrative, descriptive and argumentative texts. Besides, these texts are guided by what Guedes (2009) named discursive qualities. However, throughout the semester, the need for other strategies was observed, apart from the reading aloud. For this purpose, some other activities were added to class, such as analysis of texts written by other authors, and peer
\end{abstract}

\footnotetext{
* Doutor em Letras pela Universidade Federal do Rio Grande do Sul - UFRGS, na Linha de Pesquisa Literaturas Brasileira, Portuguesa e Luso-Africanas - professor do Colégio de Aplicação da Universidade Federal do Rio Grande do Sul (CAp-UFRGS) - Porto Alegre, Rio Grande do Sul, Brasil, adautotaufer@gmail.com

${ }^{* \star}$ Graduanda em Letras na Universidade Federal do Rio Grande do Sul - UFRGS - Porto Alegre, Rio Grande do Sul, Brasil, amelia.lovatto@gmail.com

${ }^{* \star \star}$ Doutora em Letras pela Universidade Federal do Rio Grande do Sul - UFRGS, na Linha de Pesquisa Linguística Aplicada - professora do Colégio de Aplicação da Universidade Federal do Rio Grande do Sul (CAp-UFRGS) - Porto Alegre, Rio Grande do Sul, Brasil, d.faveronetto@ gmail.com
} 


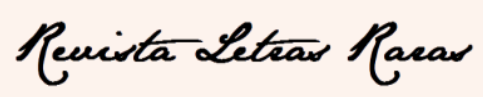

ISSN: $2317-2347$ - v. 7, n. 2 (2018)

review. These two extra activities bring to light a new discussion: what other reading activities can be developed in class in order to have a real interlocution?

KEYWORDS: Text-learning; Reading; Writing

\section{Introdução}

Este trabalho parte de um questionamento levantado em sala de aula, durante a oferta da disciplina eletiva Leitura e Produção Textual1 no Colégio de Aplicação da UFRGS (CAp-UFRGS)2, o qual será apontado em seguida. No CAp, as disciplinas eletivas são oferecidas aos alunos do Ensino Médio e têm duração de um semestre, com número de vagas é restrito a, no máximo, 15 estudantes e essa modalidade de disciplina possui carga horária reduzida: $2 \mathrm{~h} /$ aula semanais, no turno inverso. A disciplina eletiva Leitura e Produção Textual foi ofertada ao $3^{\circ}$ Ano do Ensino Médio, no primeiro semestre de 2017, contando com quinze alunos matriculados e frequentantes.

A oferta da disciplina partiu da reflexão de Endruweit e Nunes (2013) sobre os desdobramentos da enunciação escrita teorizada por Émile Benveniste em Dernières leçons (2012) para o ensino na escrita. Em suas últimas aulas no Collège de France, Benveniste dedicou atenção especial à escrita, promovendo uma reflexão precocemente interrompida em razão de sua morte. Na Aula 8, Benveniste faz a distinção entre a enunciação falada e a enunciação escrita. A teoria da enunciação benvenistiana apresenta como condição essencial da linguagem a intersubjetividade, eu e tu em constante posição de troca no discurso. Além disso, tempo e espaço determinados são exigidos para que aconteça a enunciação. O momento e o lugar de enunciação são unicamente o agora e o aqui. Dessa forma, a enunciação é apenas possível em uma relação de pessoa-espaço-tempo: eu/tu-aqui-agora. Na escrita, entretanto, essa relação é posta em xeque, uma vez que, quando escrevemos, tu não está materializado como na fala, assim como o aqui e o agora, pois, para Benveniste,

aquele que diz "agora, hoje, neste momento" localiza um acontecimento como simultâneo ao seu discurso; seu hoje pronunciado é necessário e suficiente para que o parceiro o ligue na

\footnotetext{
${ }^{1}$ Essa disciplina, sob a regência do professor Adauto Locatelli Taufer, foi ministrada em parceria com a professora Amelia Biesek Lovato, bolsista do projeto de pesquisa intitulado Ensino-aprendizagem de produção de textos argumentativos: formulando e reformulando práticas de sala de aula na educação básica cuja coordenação esteve sob a responsabilidade da professora Daniela Favero Netto. Os professores Adauto e Magali Lopes Endruweit, atuaram como professores pesquisadores nesse projeto de pesquisa.

${ }^{2}$ Doravante CAp.
} 


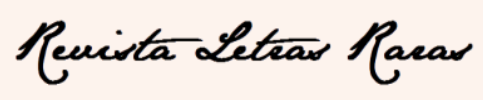

ISSN: $2317-2347$ - v. 7, n. 2 (2018)

mesma representação. Mas, separemos "hoje" do discurso que o contém, coloquemo-lo no texto escrito; "hoje" não é mais então o signo do presente linguístico pois que ele não é mais falado e percebido, e ele não pode mais enviar o leitor a algum dia do tempo crônico, pois que não se identifica como nenhuma data; ele pode ser proferido em qualquer dia do calendário e se aplicará indiferente todo dia. (BENVENISTE, 2006, p. 78). [Destaque do autor].

$\mathrm{Na}$ escrita, então, perdem-se as referências específicas da enunciação, porque o tempo e o espaço serão atualizados toda vez que o texto for lido. Ademais, acerca de tais referências, dadas as especificidades da enunciação escrita, Endruweit e Nunes (2013) discorrem sobre o momento de ausências exigido pela escrita em relação às presenças da fala e como isso se desdobra no ensino-aprendizagem da escrita:

Como substituir a confortável situação estabelecida pelo diálogo oral em uma conversa, por uma relação ausente com um interlocutor imaginado, mas nem por isso menos desconhecido? Com esse distanciamento exigido pela escrita, começam a faltar os elementos presentes na fala: se, na situação de diálogo, a fala é dirigida a alguém, situada em um contexto atual criado pela referência discursiva, na escrita, essa relação retorna sobre o próprio locutor. É um momento de ausências que a escrita exige. (ENDRUWEIT, NUNES, 2013, p. 210).

Assim, as autoras apresentam a hipótese de que a leitura pública ${ }^{3}$ em sala de aula se configuraria como um nível intermediário entre a presença do interlocutor na fala e a sua ausência na escrita. A partir dessa hipótese, fomos para a sala de aula investigar o papel que a leitura pública desenvolve no ensino-aprendizagem da escrita. Tal investigação tinha o objetivo primeiro de promover o aprimorameto dos textos dos alunos, os quais, a partir de relatos de professores dos anos anteriores, evidenciavam problemas de identificação (ou preocupação) com o interlocutor.

Embora o papel desenvolvido pela leitura pública fosse extremamente importante, durante a aplicação da prática proposta no semestre em que foi ministrada a

\footnotetext{
${ }^{3}$ Leitura pública é o exercício de leitura em voz alta em sala de aula. Partindo do pressuposto de que, normalmente, na prática da escrita em sala de aula, ocorre a ausência do interlocutor, o ato de proporcionar aos alunos a leitura de seus textos em voz alta é uma forma de criar o(s) interlocutor(es) real(is) (os colegas de sala de aula) e de desconstruir a imagem do leitor inerte. Com o exercício da leitura pública, a produção textual dos estudantes deixa de ser lida apenas pelo professor, pois esse método de trabalho com o texto viabiliza que outros interlocutores estejam presentes: o professor e os colegas. Essa metodologia, portanto, garante que, no processo de produção escrita, sejam identificados os "falantes" e os "ouvintes", que, por meio do diálogo decorrente da leitura do texto, podem contribuir para o processo de reescritura da primeira versão, lida em voz alta.
} 


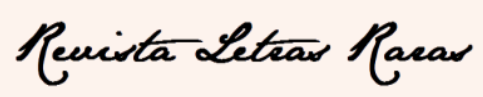

ISSN: $2317-2347$ - v. 7, n. 2 (2018)

disciplina eletiva, surgiu a necessidade de novas estratégias de ensino para aquela turma. Dentre elas, foi necessário uso de metalinguagem dos estudos do texto e de outras atividades de leitura e de revisão de textos que demonstrassem a importância da leitura e da presença de um outro no processo de aprendizagem da escrita.

As necessidades de aprendizagem do grupo, então, levaram a novos questionamentos para o ensino-aprendizagem de textos. A esses questionamentos dedicamos nossa atenção durante o semestre e é sobre eles que gostaríamos de refletir neste relato.

\section{Desenvolvimento}

As aulas da disciplina Leitura e Produção Textual seguiam a proposta de ensino de escrita do professor Paulo Coimbra Guedes (2009). O método desenvolvido pelo professor consiste em produção de narrações, descrições e dissertações norteadas pelas qualidades discursivas: unidade temática, questionamento, objetividade e concretude. $\mathrm{O}$ método também propõe a leitura em voz alta dos textos em sala de aula.

A unidade temática é a qualidade de ponto de partida; é sobre escolher um assunto e apenas um para escrever. Ela é norteadora não só para o autor - que, ao selecionar um mote de escrita, torna-se apto a selecionar o que falar sobre esse assunto , como também o é para o leitor, que passa a saber sobre o que vai ler logo no primeiro parágrafo, e assim não precisa construir sucessivas hipóteses sobre o que o texto vai tratar.

O questionamento diz a respeito ao equacionamento de um problema. Foi também a qualidade em que os alunos demonstraram maior dificuldade. $\mathrm{O}$ questionamento proporciona ao texto o espaço para o leitor participar do assunto e do problema equacionado, mostra ao leitor "que ele tem muito a ver com aquilo que o texto está falando" (GUEDES, 2009. p. 60).

A objetividade é a qualidade que trata da seleção das informações necessárias para o leitor conseguir participar do assunto sobre o qual o texto está se propondo a discutir; enquanto a concretude dá conta de mostrar essas informações e os dados textuais de forma precisa, explicitando ao leitor e garantindo que o texto contenha o que o autor quer dizer. Por exemplo, se a descrição de uma pessoa for informação essencial 


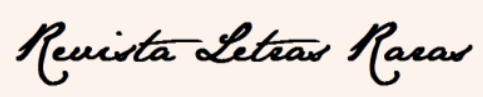

ISSN: $2317-2347$ - v. 7, n. 2 (2018)

para o texto, e o autor apenas informar que "ele era inteligente e esperto, às vezes o pensamento dele era bastante complexo", pouco o leitor conseguirá saber sobre a pessoa descrita, pois se trata de abstrações, ou seja, de adjetivos cujo sentido pode depender da interpretação do leitor.

Partindo de uma metodologia que previa a leitura pública com vistas ao aprimoramento dos textos, os alunos, após a apresentação e a discussão do tema, escreviam suas produções e, na aula seguinte, liam-nas para os demais colegas e para os professores. Entretanto, ao longo do semestre, na medida em que os alunos escreviam e apresentavam seus textos, eles revelaram dificuldades para dar conta das qualidades discursivas nas produções textuais. Tais dificuldades nos levaram a trabalhar com o estudo de outros textos, além dos produzidos por eles, identificando as sequências tipológicas nos moldes de Marchuschi (2008) e relacionando-as às qualidades discursivas. A partir do estudo dos textos, os alunos passaram a ter um conhecimento maior da metalinguagem utilizada na proposta de Guedes, pois os estudantes falavam com dada propriedade em descrição, narração, argumentação: hábito constante em aula. Porém, mesmo essa atividade tendo resolvido algumas dúvidas em relação ao funcionamento das qualidades discursivas no texto, atreladas às sequências tipológicas, seus textos ainda mostravam que eles tinham dificuldades em aplicar os conhecimentos dos pressupostos de Guedes nas suas produções.

A partir desse momento, passamos a intensificar tarefas de leitura e de discussão em sala de aula, tanto de textos produzidos por eles — fazendo revisão em pares quanto a leitura e a análise de textos escritos por outras pessoas. ${ }^{4}$ As qualidades discursivas continuavam sendo norteadoras das tarefas de leitura, ou seja, os alunos deveriam identificar nos textos a ausência ou a presença delas.

A disciplina eletiva, por sua vez, já partia do pressuposto da importância da leitura dos textos produzidos pelos alunos em sala de aula para a aprendizagem da escrita. Contudo, o que se somou a essa suposição foi a importância de diferentes tarefas de leitura para a aprendizagem da escrita, bem como a presença de um leitor crítico (na figura dos colegas que participavam daquela mesma esfera), além dos professores, para participar da interlocução.

\footnotetext{
${ }^{4}$ Textos escritos pelos estudantes do Bacharelado em Letras da Universidade Federal do Rio Grande do Sul que frequentaram a disciplina Leitura e Produção de Textos em Língua Portuguesa I, ministrada pela professora Magali Lopes Endruweit.
} 


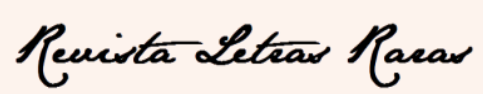

ISSN: $2317-2347$ - v. 7, n. 2 (2018)

Para fazermos uma análise mais aprofundada das tarefas de leitura em sala de aula, apresentaremos duas subseções, com as descrições das tarefas e do papel desenvolvido por elas na escrita dos alunos.

\subsection{Análise de textos para além dos produzidos em sala de aula}

A disciplina eletiva Leitura e Produção de Textos oferecida no CAp é uma adaptação da disciplina Leitura e Produção de Textos em Língua Portuguesa I, oferecida ao curso Bacharelado em Letras na UFRGS e ministrada semestralmente pela professora Magali Lopes Endruweit.

Para fins de análises textuais nos moldes dos produzidos pelos alunos na disciplina eletiva, buscamos as produções escritas pelos alunos do Bacharelado em Letras. Os textos lidos e analisados eram selecionados de acordo com a proposta. Por exemplo, a descrição de pessoa foi uma proposta de produção textual que, a partir da leitura das escrituras de primeira versão, necessitou de uma análise de texto que pudesse exemplificá-la. Com auxílio do projetor, mostramos uma produção textual aos alunos para fazermos uma análise quanto à presença ou ausência das qualidades discursivas.

Realizamos uma leitura por parágrafos, a partir de um esquema de texto que tínhamos previamente estudado em aula, como a organização a seguir:

$1^{a}$ parte - Bronca: Apresentar ao leitor o que incomoda o autor, ou seja, do que o texto vai tratar.

$2^{a}$ parte - Exemplo pessoal (narrativo/descritivo): Dar concretude à bronca aludida na primeira parte.

$3^{a}$ e $4^{a}$ partes - Por quê?: De que forma o exemplo escolhido ilustra a bronca?

Qual a relevância dele para o texto? (Isso deve estar explícito).

$5^{a}$ parte-Universalizar: Trazer um exemplo universal, que toque a todos.

$\sigma^{a}$ parte - Por quê??: Mostrar o motivo pelo qual o exemplo toca a todos.

Dessa forma, os alunos tiveram de identificar: 1) como a organização textual contribuiu para a presença das qualidades discursivas; e 2) como as sequências tipológicas atrelavam-se às qualidades discursivas. 


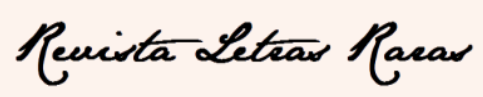

ISSN: $2317-2347$ - v. 7, n. 2 (2018)

\subsection{Revisão em pares}

Após a produção da primeira versão do texto, aliamos à tradicional leitura pública realizada durante as aulas a revisão em pares, para que os alunos propusessem uns aos outros os encaminhamentos para a reescrita. Desta vez, a primeira versão não passaria pelas mãos dos professores. Assim, os alunos deveriam atentar para: a) a presença ou ausência das qualidades discursivas na primeira versão; e b) o modo como o autor deveria reescrevê-la a fim de aprimorar sua produção.

Os alunos reuniram-se em duplas e trocaram os textos entre si. A partir dessa troca, eles deveriam ler, analisar e propor encaminhamentos ao texto, conforme a atividade descrita em 2.1, sendo que, desta vez, eles poderiam fazer sugestões mais livres, como apontar a presença e o detalhamento da bronca e o aprofundamento de uma ou outra qualidade discursiva, por exemplo, para a reescrita. Nesse sentido, essa atividade lançou mão da presença de um interlocutor real, aquele que, em tese, nesse intercâmbio entre os pares, teve a função de atuar como um crítico leitor e de propor encaminhamentos para uma nova versão do texto produzido pelo colega de dupla, pois, de acordo com Araujo (2004):

Como na produção de linguagem oral quem enuncia beneficia-se do controle exercido pelo interlocutor, na produção escrita, a presença de um interlocutor real que releia e revise o texto junto com o produtor deverá multiplicar o potencial "dialógico" interno deste, favorecer a internalização do diálogo produtor-leitor. Esse interlocutor, mesmo um par não necessariamente mais experiente, seria um "representante do leitor" que negocia sentidos com o autor e aponta as exigências de compreensão da perspectiva do leitor, ajudando a configurar esse "diálogo interior". Isso conduz o sujeito que escreve e desenvolve ações reflexivas na escrita (GOÉS, 1993), permite-lhe ocupar melhor a função de leitor de si mesmo e o conduz a uma regulação cada vez mais autônoma de suas próprias produções." (ARAUJO, 2004, p. 55). [Destaques do autor].

Dessa forma, a revisão em pares vai ao encontro da hipótese inicial norteadora da disciplina eletiva. Contudo, diferentemente do que propõe Araujo, o leitor crítico/revisor do seu texto não é apenas uma representação; ao ler a produção escrita do 


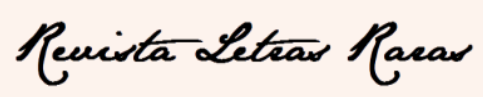

ISSN: $2317-2347$ - v. 7, n. 2 (2018)

colega, ele se torna leitor; ao revisar, revisor. Diante dos textos escolares, essa é uma postura importante, pois os alunos escrevem, também, para que seus textos sejam lidos. A sala de aula é uma representação social real. Nela em que se produz conhecimento para si e para o grupo, o que permite a identificação ou não com os integrantes do grupo. Um exemplo claro disso foi quando um dos alunos escreveu uma história que, quando compartilhada com os colegas, provocou risos e comentários. Devido à identificação dos leitores com o assunto, houve, portanto, envolvimento do interlocutor como o tema abordado pelo colega durante a leitura. Esse reconhecimento mostrou que os alunos queriam e, principalmente, tinham o que dizer uns aos outros: seus colegas, seus leitores.

A revisão por pares foi uma prática que contou com a aprovação dos alunos, pois, nos debates realizados após a revisão e a leitura pública dos textos, eles mencionaram que se sentiram, de fato, contribuindo para o aprimoramento das escrituras dos pares e dos demais colegas do grupo. Essa prática, na visão deles, foi muito importante porque se sentiram totalmente inseridos no processo de produção textual coletiva, atuando como produtores e como interlocutores das produções textuais. A troca entre o leitor e o autor deu espaço para mais um aprendizado que, inclusive, contempla a objetividade, pois essa qualidade discursiva permite que o autor, no momento de escrita, consiga reconhecer as dificuldades possíveis do leitor, antecipando essas informações e facilitando a compreensão da leitura.

O resultado desta atividade, apresentado a seguir, pode ser exemplificado por meio de um texto descritivo ${ }^{5}$ (primeira versão e sua reescrita) ${ }^{6}$ produzido por um dos estudantes matriculados na referida disciplina eletiva.

\section{TEXTO DESCRITIVO (primeira versão) ${ }^{7}$}

Meu pai, carregando a pseudo juventude de um homem de 53 anos, é dotado de um andar confiante, daqueles em que apenas o atrito do calcanhar, coberto pelo engraxado sapato preto, com o solo, emite um respeitoso ruído. É um homem alto o suficiente para, quando desprecavido, adquirir um bom machucado na cabeça ao acomodar-se em um automóvel.

\footnotetext{
${ }^{5}$ A atividade consistiu em produzir uma descrição de pessoa.

${ }^{6}$ Devido aos limites de extensão desse relato de experiência, selecionamos apenas um texto (primeira versão e reescrita) para exemplificar nossas reflexões sobre uma prática de ensino de texto.

${ }^{7} \mathrm{O}$ autor não atribuiu título à primeira versão de seu texto.
} 


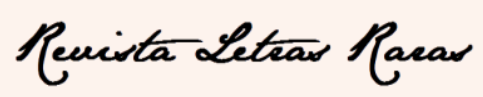

ISSN: $2317-2347$ - v. 7, n. 2 (2018)

Além disso, carrega em seu físico um leve sobrepeso que insiste em se manifestar em forma de protuberância abdominal, decorrente de sua eloquente paixão por paçoca de amendoim. Protuberância esta que, apesar da presença, não obtém protagonismo evidente ao ser contrastada por seu porte atlético traçado por uma larga e robusta estrutura de ombros, tendo sido essa, gerada em duros anos de treinamento no exército militar, o que implica em buscas mais complicadas e obstruídas ao tentar adquirir uma camiseta confortável. Dono de uma careca reluzente na parte superior da cabeça, exibe com prazer os seus resquícios laterais de fios capilares cuja coloração já se faz, notoriamente, prateada.

Em seu dia-a-dia, apresenta uma alegre e inspiradora forma de se postar, com o peito aberto como um pombo e com a cabeça tão erguida a ponto de não parecer exagero supor que existe um fio de nylon a puxando para cima. Porém, quando em um diálogo, toda essa tensão para o alto deixa de existir e, lentamente, passa a direcionar seus olhos que, de forma suave, passam do azul para o verde, como o degradê de um oceano em uma manhã de sol, até que encontram a pessoa com que busca dialogar. Se veste de maneira muito objetiva, adaptando-se sob medida às situações a que busca executar, alternando do sóbrio e lúcido terno grafite, nos desgastantes dias de trabalho, até a florida e excessivamente estampada bermuda para deleitar-se as domingos e feriados.

À primeira versão da produção escrita, a partir da leitura pública em sala de aula, foram feitas algumas observações e considerações para o encaminhamento de sua reescrita. Ao lermos a primeira versão do texto produzido pelo estudante, é possível percebermos que a bronca, ou seja, o questionamento, não está presente. A descrição de pessoa não está a serviço de uma bronca, por isso, é difícil para o leitor criar um vínculo e, portanto, estabelecer um diálogo com a descrição apresentada. O que isso significa? A primeira versão do texto descritivo não equaciona um problema do qual o leitor pode ou se sente convidado a participar, embora haja uma descrição prática e bem elaborada de pessoa.

A descrição de pessoa desenvolvida e apresentada pelo aluno, entretanto, não correspondeu ao tipo de produção textual que era esperada, considerando as qualidades discursivas postuladas por Guedes (2009), as quais nortearam a proposta de prática apresentada aos alunos. Ao se considerarem tais qualidades para a escritura do texto, é necessário equacionar um problema que dialogue com o leitor, que o convide a participar do conteúdo textual produzido pelo estudante; enfim, que faça com que o leitor se sinta contemplado no texto. Somente assim é possível apresentar um 


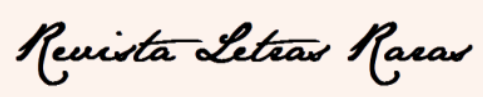

ISSN: $2317-2347$ - v. 7, n. 2 (2018)

questionamento. A bronca ou questionamento, portanto, deve promover identificação entre autor e leitores, ouvintes para o caso do texto de leitura pública em sala de aula.

Tendo em vista tais considerações e observações à escritura do texto descritivo, foram feitas as seguintes perguntas, ${ }^{8}$ considerando a ausência do questionamento na descrição de pessoa apresentada pelo estudante, como forma de encaminhamento à atividade de reescrita textual: 1) Por que descrever o pai? 2) Que discussão o autor quer provocar com isso? 3) De que forma a descrição do pai ajuda a fomentar essa discussão? 4) O que, sobre o pai, é preciso contar/descrever para contribuir com a discussão efetivamente?

A seguir, apresentamos a reescrita do texto, considerando as sugestões realizadas a partir da leitura pública em sala de aula:

\section{RESPONSABILIDADE VITALÍCIA (reescrita)}

Desde que viemos ao mundo, estamos fadados a lidar com expectativas externas, isso é um fato. Seja da vizinha da casa ao lado, ou do professor da nossa matéria favorita, variando apenas em forma e medida. A verdade é que esse intenso depósito de sonhos alheios, misturados com frustração e despejados com um fundo de esperança em cima de nós, geralmente vêm disfarçados de conselhos, dicas ou qualquer espécie de guru. Desde a pressão de seu treinador de vôlei para que você deixe de encarar isso como um hobby e passe a fazer deste esporte o seu cotidiano, até o veto de nossos parentes às preferências de nossas vidas, sejam elas no âmbito profissional, sexual ou qualquer outro. Porém, até que ponto essas condições, que nos são impostas, nos fazem mais felizes? Seriam estes, conselhos adequados às nossas próprias e singulares realidades, em suas mais intrínsecas distinções?

Quando me deparo com demasiadas expectativas alheias em minha vida que por alguns descuidos meus, podem afetar o rumo que virei a decidir para a minha jornada, decido ficar presente o mais rápido possível e lembrar do meu grande exemplo para tantas coisas e que também me herda grandes lições neste nicho de nosso cotidiano, meu pai.

Sempre dotado de um andar confiante, daqueles que apenas ao tocar o solo com seu sapato preto, é capaz de emitir um suave e respeitoso som, além de sua firme e inspiradora postura que, quando de pé, esculpe no ar um formato de pombo, com a estrutura peitoral fortemente aberta $e$ estabilizada, em harmonia com a sua cabeça erguida, em uma posição na qual não seria nenhum exagero supor a existência de um fio de nylon que a

\footnotetext{
${ }^{8}$ As perguntas foram elaboradas pelos professores.
} 


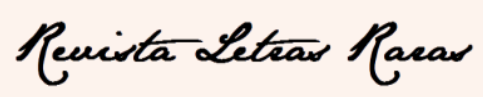

ISSN: $2317-2347$ - v. 7, n. 2 (2018)

mantém para cima. Meu pai sempre foi assim, desde o tempo em que se encontrava com dificuldades para os mais básicos cálculos de matemática e vivia sua luta para chegar, suando, em primeiro lugar na sala de aula, após o recreio na pracinha com os seus coleguinhas. Isso se refletia em sua personalidade.

Enquanto cursava o Ensino Médio, sofria forte pressão paterna para ser aquele idealizado aluno-máquina que devorava entediantes livros didáticos, vivia para reproduzir conteúdos com o mesmo nível de interesse e carecia de confiança para relacionar-se com outras pessoas. Teve então, o mesmo peito (aquele, de pombo) para decidir que assumiria o controle sobre o seu estilo de vida, para além das expectativas de seu pai, com a condição de manter-se aprovado em suas obrigações. Com isso, canalizou suas energias para o desenvolvimento de seu potencial de relações interpessoais, fortificando e impondo a sua voz até alcançar um timbre digno de narradores futebolísticos em jogos decisivos de seus times do coração. Melhora esta, facilmente evidenciada a partir do momento em que me deparo com seus olhos, fixos e celeste, em meio a uma troca de ideias e experiências. Adotou atividades que desenvolveriam seu corpo e também ampliariam as suas capacidades cognitivas, bem como a sua confiança, como o vôlei e o futebol, esportes praticados até que seus ligamentos do ombro suplicassem por atendimento, vitima de uma repentina distensão. Devido a essas escolhas e a um conhecimento fundamentado, de forma equilibrada, destacou-se no meio profissional, sempre acreditando em suas próprias decisões, buscando por propósitos reais para a verdade por trás de sua existência, assumindo inteira responsabilidade pela mesma.

Com este exemplo, tive a oportunidade de refletir muito e chegar à conclusão de que ninguém, por mais óbvio que soe, pode saber mais de nossas vidas, preferências, verdades e sentimentos, do que nós mesmos. Nós não somos pequenas cartas de um jogo infantil, cujas habilidades $e$ fraquezas já são previamente definidas, mantendo-se em uma mesma forma até a eternidade. Paradoxalmente, isso é o que acontece com quem se sujeita a passar a vida reproduzindo o que não lhe agrega e tampouco condiz com o que lhe atrai, sendo fiel à verdade dos outros, um grande traidor frente a sua própria. Quando assumimos o controle das nossas vidas, estamos automaticamente manuseando o volante que nos guia a uma vida mais feliz e autêntica, na mesma medida em que nos distanciamos de um paradigma abundante em medo e conformismo, plenamente voltado a busca pela aceitação de terceiros.

Na reescrita textual, agora sob o título de Responsabilidade Vitalícia, é possível perceber que houve um salto qualitativo em relação à qualidade discursiva questionamento, uma vez que já no primeiro parágrafo, sem adentrar no exercício da descrição propriamente dita, o leitor se sente convidado a participar do texto quando lê: “A verdade é que esse intenso depósito de sonhos alheios, misturados com frustração e despejados com um fundo de esperança em cima de nós, geralmente vêm disfarçados de 


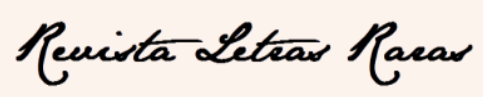

ISSN: 2317-2347 - v. 7, n. 2 (2018)

conselhos, dicas ou qualquer espécie de guru”. Esse trecho, em que o autor lança mão da primeira pessoa do plural, aproxima o leitor do relato, incluindo-o na problematização e fisgando-o para a leitura da descrição. E a bronca termina de ser exposta quando o autor afirma: "Quando me deparo com demasiadas expectativas alheias em minha vida que por alguns descuidos meus, podem afetar o rumo que virei a decidir para a minha jornada, decido ficar presente o mais rápido possível e lembrar do meu grande exemplo para tantas coisas e que também me herda grandes lições neste nicho de nosso cotidiano, meu pai”. Ainda no que tange à habilidade de envolver o leitor, Netto menciona que o questionamento "é a qualidade discursiva que diz respeito à capacidade do autor de envolver o leitor com o assunto do texto, isto é, trata-se de um gancho que, de certa forma, instigará o leitor a participar do diálogo proposto pelo autor" (NETTO, 2017, p. 81). Nesse sentido, este trecho produzido pelo estudante contém o gancho que prende o leitor ao texto: apresenta ao leitor o objeto textual e justifica a escolha feita pelo autor, artifício que conquista a atenção de quem lê.

\section{Considerações finais}

A oferta da disciplina Leitura e Produção Textual fomentou uma reflexão mais aprofundada acerca do processo de ensino-aprendizagem da escrita, além de proporcionar a criação de novas estratégias de ensino de acordo com as necessidades emergentes dos alunos. Como vimos neste relato, é importante ao professor que fomenta a prática constante de escrita criar estratégias que auxiliem seus estudantes a serem capazes de dirimir a abstração que caracteriza essa atividade. A proposição dessas estratégias é relevante à eficácia para as práticas de leitura e escrita em sala de aula.

Além disso, as conclusões deste trabalho corroboram com a hipótese de Endruweit e Nunes (2013) de que a leitura pública se configuraria como um nível intermediário entre a presença do interlocutor na fala e a sua ausência na escrita, uma vez que vemos a importância de se criar em sala de aula um ambiente de dizeres, isso é, um ambiente em que se pode dizer algo para alguém que ouvirá o que está sendo dito e responderá ao que ouve. A participação dos colegas na atividade de revisão textual em pares mostrou-se relevante para a aprendizagem justamente por proporcionar esse 


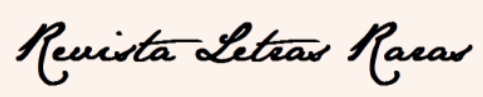

ISSN: $2317-2347$ - v. 7, n. 2 (2018)

espaço de troca de experiências e de percepções a respeito da escrita. Já a atividade de análise funcionou como uma construção de parâmetros para serem avaliados, constituindo a revisão de texto feita pelos colegas. Assim, o trabalho conjunto de análise e de revisão textuais se complementam para o aprimoramento da produção escrita dos alunos.

Por fim, entendemos que essas práticas em sala de aula preparam os alunos não apenas para a produção textual, mas também os familiarizam com as práticas textuais do mundo. A análise e a revisão, na verdade, são artifícios que devem ser permanentes porque são constitutivas da escrita. Ao realizarem tais procedimentos com as produções escritas dos colegas, são oferecidas possibilidades para que os alunos passem a analisar e revisar seus próprios textos, emancipando a escrita e favorecendo a constituição de mais autoria no exercício da escritura, que deve ser permanente.

\section{REFERÊNCIAS}

ARAUJO, L. C. Reescrevendo a escrita na escola: a prática de revisão e reescrita textual mediada por pares. Salvador, Universidade Federal da Bahia, Faculdade de Educação, 2004.

BENVENISTE, E. Problemas de linguística geral I. Campinas, Pontes, 2005.

ENDRUWEIT, M. L; NUNES, P. A. O ensino da escrita visto pela ótica enunciativa: é possível ensinar uma ausência?. In Calidoscópio; Vol. 11, n. 2, p. 204-213, mai/ago 2013.

GUEDES, P. C. Da redação à produção textual: o ensino da escrita. São Paulo, Párabola Editorial, 2009.

MARCUSCHI, L. A. Produção textual, análise de gêneros e compreensão. São Paulo: Parábola Editorial, 2008.

NETTO, D. F. Produção textual: formulando e reformulando práticas de sala de aula. Jundiaí: Paco Editorial, 2017.

Recebimento: 15/12/2017

Aceite: 16/09/2018 